\title{
Structural Analysis Programme Based on the Equivalent Column's Method
}

\author{
Hulea Radu, Parv Bianca, Nicoreac Monica and Petrina Tudor \\ Department of Structural Mechanics, Faculty of Civil Engineering, Technical University Cluj-Napoca, Romania
}

\begin{abstract}
The focus of this article is to accomplish a program using MatLab software, which will determine the global behavior of the structure, the stress, stability and frequency of the tall building with " $n$ ” levels. The program starts with the global analyses based on the equivalent column theory. The central core consists of reinforced concrete shear walls of the elevator's tubes and of the staircase, design to resist the lateral loads. Applying the equivalent column's theory, the bracing system will be replaced by an equivalent column, considered to be a vertical cantilever fixed at the base and the loads will be applied in the shear center axis. The program using mathematical and physical relations, has as input dates the geometrical and stiffness characteristics of the plan of the building and as output dates the critical load, the fundamental frequency, the maximum stresses and deformations of the structure.
\end{abstract}

Key words: Tall structure, equivalent column, central core.

\section{Introduction}

The focus of this article is to accomplish a program using Matlab software which will determine the response of a tall structure with " $n$ " levels. The program is based on an approximate calculation method, in which the theory of equivalent column is applied.

Reinforced concrete structures with central cores act as a vertical cantilever, fixed at the base. All structural elements that resist horizontal loads will be replaced by an equivalent column.

To simplify the calculation method and to give a more accurate method, only the structural elements capable of resisting the lateral loads will be taken into consideration: shear walls, spandrels and central cores. It is assumed that the effect from nonstructural elements is insignificant. The structural system consists of reinforced concrete shear walls and central cores are subjected to wind loads. Horizontal loads develop bending moments, shear forces and in most cases torsion moment, having the maximum value at

Corresponding author: Parv Bianca, PhD student, research fields: structural mechanics. E-mail: bianca.parv@mecon.utcluj.ro. the base of the structure and increasing along with the building's height.

The structure's behavior under the action of horizontal loads becomes very complex and represents the main problem in structural analysis of tall buildings. Approximate calculation method is based on analytical procedures of calculation, on physical and mathematical formulas, and can be used to verify the results obtained by exact calculation, based on finite element method. If both methods of calculation give similar results, indicate that the method of calculation has been applied correctly. This verification is very important, because some errors are very difficult to detect applying the exact method of calculation.

A source code in MatLab comes to help those who wish to perform a manual computation in order to verify and compare the results obtained by the FEM. It is important to know the theories underlying the structural analysis, not only to verify or compare the results obtained by FEM but also to develop new computational program.

\section{The Equivalent Column's Method}

The global analysis of a tall building is based on the equivalent column theory and civil engineering 
theorems. By applying the approximate analysis of the equivalent column, it will simplify certain formulas and will obtain the maximum stresses and deformations of the elements, the critical loads and the fundamental frequency of the structure. The calculation method allows some approximations which brings the mathematical formulas to a simple form, thus it can be performed manually without difficulty.

To determine the stresses in shear walls or central cores, under the action of uniformly distributed loads, is assumed that the material is: homogeneous, isotropic and follow Hooke's law.

The monotone character of shear walls, having constant thickness throughout the building's height, without geometrical imperfections, has allowed the systematization of calculation model in more simple form, which can be used without difficulty in a manual calculation model. The stiffness of the structure is considered to be constant throughout the height of the equivalent column. The geometrical and stiffness characteristics of the elements are used for the determination of lateral deformations and sectional stresses of the shear walls or cores.

When calculating the central cores of a tall structure, the lateral stiffness is large enough to resist horizontalloads, including the effects of torsion. It will take into consideration the tri-dimensional behavior for the simplified calculation method. Compared with central cores or shear walls, the frames are more flexible and often the lateral stiffness is neglected [2].

The bracing elements capable of resisting horizontal loads will be reduced to an equivalent column, forming a cantilever element, whose bending and torsional stiffness represents the whole structural stiffness. The deformation of the cantilever is also influenced by the rotation of foundation caused by the soil compression. A simplifying assumption that can be adopted to neglect the influence of the rotation of foundation on the structure is by considering the shear walls or cores fixed at the base [4].

By considering the structure as a vertical monotonous system and by admitting the others simplifying assumptions given above, the physical and mathematical formulas will depend on a smaller number of parameters, fact that will facilitate the way for obtaining the final results. It is important to reduce the number of parameters, but we have to know exactly which parameters can be reduced for obtaining the results closer to reality [1].

The computer program developed in Matlab, has as input data the geometrical and stiffness characteristics of the building.

The first step is to determine the shear center position which depends only on geometrical and stiffness characteristics of the structure. The equivalent column position is located at the shear center of the structure. The shear center is important in relation to transverse forces. If lateral forces are applied in the shear center, the structure will be subjected only to bending. If lateral forces are not applied in the shear center, the structure will not only bend, but will be also subjected to torsion and warping.

In general the central core structures are mono-symmetric or double symmetric, fact that simplifies the determination of shear center position.

For each structural element will determine: $I_{x, i}, I_{y, i}$ - moments of inertia on both directions; $\mathrm{I}_{\mathrm{xy}, \mathrm{i}}$-product of inertia; $\mathrm{x}_{\mathrm{i}}, \mathrm{y}_{\mathrm{i}}$-distance between centroid and shear center; Iw-warping constant and J - Saint-Venant torsional constant.

It is also necessary to determine the moment of inertia IX, the product of inertia IXY, the warping constant IW and the Saint-Venant torsional constant J, for the whole bracing system reduced to an equivalent column. The formulas given below are for " $n$ " structural elements.

As input data each parameter will be introduced in the form of a vector that contains values for each item.

$$
\begin{gathered}
\mathrm{I}_{\mathrm{X}}=\sum_{1}^{\mathrm{n}} \mathrm{I}_{\mathrm{x}, \mathrm{i}} ; \mathrm{I}_{\mathrm{Y}}=\sum_{1}^{\mathrm{n}} \mathrm{I}_{\mathrm{y}, \mathrm{i}} ; \mathrm{I}_{\mathrm{XY}}=\sum_{1}^{\mathrm{n}} \mathrm{I}_{\mathrm{xy}, \mathrm{i}} \\
\mathrm{J}=\sum_{1}^{\mathrm{n}} \mathrm{J}_{\mathrm{i}} \\
\mathrm{I}_{\omega}=\sum_{1}^{\mathrm{n}} \mathrm{I}_{\omega, \mathrm{i}}+\mathrm{I}_{\mathrm{x}, \mathrm{i}} \mathrm{x}_{\mathrm{i}}^{2}+\mathrm{I}_{\mathrm{y}, \mathrm{i}} \mathrm{y}_{\mathrm{i}}^{2}-2 \mathrm{I}_{\mathrm{xy}, \mathrm{i}} \mathrm{x}_{\mathrm{i}} \mathrm{y}_{\mathrm{i}}
\end{gathered}
$$


The Iw parameter represents the warping torsional resistance of the core. The warping constant is a weighted sum which is calculated in a coordinate system whose origin is the global shear center [Beck, Konig and Reeh, 1968].

The warping constant, takes into account the warping torsion of each bracing element and also the bending torsion of each element.

The geometrical and stiffness characteristics represent the input data of the computer program developed in MatLab.

In the computer program should also be introduced the longitudinal modulus of elasticity $\mathrm{E}$, the modulus of elasticity in shear $G$, the number of levels $n$, the building's height $\mathrm{H}$, the in plan dimensions $\mathrm{B}$, $\mathrm{L}$, the wind loads in both directions qx, qy, the weight per unit volume of the building (for dynamic analysis) $\gamma$ and the gravity acceleration g. The following formulas are developed by KarolyA.Zalka [1].

\subsection{Step1: Determination of Critical Load}

To determine the critical load on the two main directions (x, y), for a cantilever loaded with constant uniformly distributed load, the code uses formulas from Timoshenko theory:

$$
\begin{gathered}
\text { Ncr.x }=7.84 *{ }^{*}{ }^{*} E^{*} \operatorname{sum}\left(\text { Iyi) } / \mathrm{H}^{\wedge} 2\right. \\
\text { Ncr.y }=7.84 *{ }^{*} \text { r }^{*} \mathrm{E}^{*} \operatorname{sum}(\mathrm{Ixi}) / \mathrm{H}^{\wedge} 2
\end{gathered}
$$

Where:

$\mathrm{rs}=\mathrm{n} /(\mathrm{n}+1.6)$;

$\mathrm{n}$ - number of levels

Determine the parameter $\mathrm{k}$ for torsion using the formulas below:

$$
\begin{aligned}
\mathrm{k} & =\mathrm{H}^{*} \operatorname{sqrt}\left(\mathrm{G}^{*} \mathrm{~J} /\left(\mathrm{E}^{*} \mathrm{Iw}\right)\right) \\
\mathrm{ks} & =\mathrm{k} / \mathrm{sqrt}(\mathrm{rs})
\end{aligned}
$$

Where:

$\mathrm{G}^{*} \mathrm{~J}$ - the shear torsional rigidity of the core $\mathrm{E}^{*} \mathrm{I}_{\mathrm{w}}$ - the warping rigidity of the core

After determining theks parameter, the program will require the introduction of $\alpha$ parameter (critical load parameter, eigenvalue of pure torsional buckling) in order to calculate the critical loads for pure torsion.

$$
\text { Ncr.pt=alfa*rs*E*Iw/(ip^ } \left.{ }^{\wedge} * \mathrm{H}^{\wedge} 2\right)
$$

Karoly A. Zalkaproposes an exact method of calculation which defines the coupling of the basic modes and which can be used for the calculation of critical load of the combined sway-torsional buckling if the basic critical loads (Ncr.x, Ncr.y, Ncr.p) are known.

The method requires the determination of parameters $\zeta \mathrm{x}, \zeta \mathrm{y}$ (depending on the position of the center of gravity and radius of gyration, the parameters that take into account the mass eccentricity) and the coefficients involved in solving the cubic equation.

\subsection{Step2: Determination of Fundamental Frequency}

Similarly, the program contains a sequence of code for calculating the natural frequency on both principal direction and torsional frequency. The calculation is based on formulas developed by Timoshenko (circular frequencies) for a cantilever loaded by a constant uniform load. Of the three frequencies, the most important is the frequency with the lowest value, being the fundamental frequency of the building.

$$
\begin{aligned}
& \mathrm{fx}=0.56 * \mathrm{rf} * \operatorname{sqrt}\left(\mathrm{E}^{*} \mathrm{Iy} \mathrm{y}^{*} 10^{\wedge} 3 /\left(\mathrm{sig}^{*} \mathrm{~A}\right)\right) / \mathrm{H}^{\wedge} 2 \\
& \text { fy }=0.56 * r{ }^{*} \operatorname{sqrt}\left(E^{*} \mathrm{Ix}^{*} 10^{\wedge} 3 /\left(\operatorname{sig}^{*} \mathrm{~A}\right)\right) / \mathrm{H}^{\wedge} 2 \\
& \text { f.tp=n1*rf*sqrt( }\left(E^{*} \mathrm{Iw}^{*} 10^{\wedge} 3 /\left(\operatorname{sig}^{*} \mathrm{~A}\right)\right) /\left(\mathrm{ip} * \mathrm{H}^{\wedge} 2\right)
\end{aligned}
$$

Where:

rf $=\operatorname{sqrt}(\mathrm{n} /(\mathrm{n}+2.6))$-reductionfactor, dependents on levels number.

\subsection{Step3: Determination of Maximum Stresses and Deformations}

Under the action of horizontal loads, the equivalent column develops displacements and rotations in both directions. The maximum displacementoccurs on top of the building, so the parameters will be: the building's height, the modulus of elasticity, the constant uniform load and will take into account the slope of a trapezoidal lateral load. To determine the displacement and rotation we need to resolve the 4th degree differential equations developed by Vlasov, which define the bending and torsion of the equivalent 
column. The formulas that we use in the code to determine the maximum displacement at level $\mathrm{H}$ are: Maximum Displacement

$$
\begin{aligned}
& \mathrm{u}_{\max }=\mathrm{H}^{\wedge} 4^{*}\left(\mathrm{qxb} /\left(\mathrm{E}^{*} 10^{\wedge} 3\right)\right)^{*}\left(1 / 8+\mathrm{miu}^{*} 11 / 120\right) \\
& \mathrm{v}_{\max }=\mathrm{H}^{\wedge} 4^{*}\left(\mathrm{qyb} /\left(\mathrm{E}^{*} 10^{\wedge} 3\right)\right)^{*}\left(1 / 8+\mathrm{miu}^{*} 11 / 120\right)
\end{aligned}
$$

Maximum Rotation

$\mathrm{R}_{\max }=\left(\mathrm{m}_{\mathrm{xz}} * \mathrm{H}^{\wedge} 2 /\left(\mathrm{G}^{*} \mathrm{~J}\right)\right)^{*}\left((1+\mathrm{miu}) *(\cosh (\mathrm{k})-1) /\left(\mathrm{k}^{\wedge} 2^{*} \mathrm{co}\right.\right.$ $\operatorname{sh}(\mathrm{k}))-\left(1+\operatorname{miu} / 2-\mathrm{miu} /\left(\mathrm{k}^{\wedge} 2\right)\right) * \tanh (\mathrm{k}) / \mathrm{k}+1 / 2+\operatorname{miu} / 3-\operatorname{miu}$ $\left./\left(\mathrm{k}^{\wedge} \mathrm{2}\right)\right)$

The maximum limit of displacement for tall buildings is between $\mathrm{H} / 400$ and $\mathrm{H} / 600$, design codes recommend a limitation of movement lower than $\mathrm{H} / 500$. The condition is sufficient to provide comfort for activities performed in the building. Thus, the computer program has the condition that the movement should not exceed $\mathrm{H} / 500$, otherwise it is recommended to increase the elements rigidity or the elements position.

To determine the shear forces of the equivalent column we considered a static determined structure of a cantilever fixed at the base. The shear forces are obtained by integrating the equations that define the external load. The parameters for the determination of shear force are: building height, uniformly distributed load, the slope of the trapezoidal load, bending stiffness of the structural system and the effect of rotating around the center of the shear.

Txmax $=\mathrm{H}^{*}(1+\mathrm{miu} / 2) *(\mathrm{Iyi}(\mathrm{i}) * \mathrm{qxb}+\mathrm{Ixyi}(\mathrm{i}) * \mathrm{qyb})-(\operatorname{Iyi}(\mathrm{i})$ *yi(i)-Ixyi(i)*xi(i))/Iw*mx.z*H*EtaTmax

Tymax $=\mathrm{H}^{*}(1+$ miu/2)*(Iyi(i)*qxb+Ixyi(i)*qxb)+(Ixi(i )*xi(i)-Ixyi(i)*yi(i))/Iw*mx.z*H*EtaTmax

The equation for determining the bending moment in each structural element is obtained by integrating the equation that defines the shear force. To determine the bending moment for each structural element we need to take into consideration the torsion around the shear center and the effect of the rotation over the structural elements. The bending moment value depends on several parameters: the height of the structure, uniformly distributed load of wind and bending stiffness of the structural system.
Mxmax $=-\left(\mathrm{H}^{\wedge} 2 / 2\right) *(1+2 * \operatorname{miu} / 3) *(\operatorname{Iyi}(\mathrm{i}) * \mathrm{qxb}+\operatorname{Ixyi}(\mathrm{i}) * \mathrm{q}$ yb)+((Iyi(i)*yi(i)-Ixyi(i)*xi(i))*mx.z*H^2)/(Iw*2)*Et aMmax

Mymax $=-\left(\mathrm{H}^{\wedge} 2 / 2\right) *(1+2 * \operatorname{miu} / 3) *(\operatorname{Ixi}(\mathrm{i}) * \mathrm{qyb}+\operatorname{Ixyi}(\mathrm{i}) * \mathrm{q}$ xb)-((Ixi(i)*xi(i)-Ixyi(i)*yi(i))*mx.z*H^2)/(Iw*2)*Eta Mmax

If external load is not applied to the shear center of the structural system, the equivalent column will be subjected to torsion. By deriving the equivalent column equation of rotation we obtain the Saint-Venant torsional moment and by calculating the 3rd derivate equation we obtain the warping torsional moment. Depending on parameter $\mathrm{k}$ and external load is obtained the height at which maximum torsion occurs. Therefore, the computer program after determining the parameters $\mathrm{k}$ and the external load, it will introduce the $\mathrm{z} / \mathrm{H}$ ratio. The Saint-Venant torsional moment is zero at the bottom of the building while the warping torsional moment has maximum value at the bottom of the building.

\section{Solving the Cubic Equation for Determining the Critical Load and Fundamental Frequency}

The critical force is determined usingthe exact method by solving Eq. (19). This equation takes into consideration the critical forces for the two main directions and the critical force of rotation. The lowest value from the solutions of the cubic equation represents the combined force of loss of stability.

$$
N^{3}+a_{2} \cdot N^{2}+a_{1} \cdot N^{2}-a_{0}=0
$$

Where: $a_{0}, a_{1}, a_{2}$, depend on: Ncrx, Ncry, Ncr $\varphi$

To determine the critical frequency we will solve the cubic Eq. (20). This equation combines the three main frequencies. The lower value of the cubic equation solutions represents the critical frequency.

$$
\left(f^{2}\right)^{3}+a_{2} \cdot\left(f^{2}\right)^{2}+a_{1} \cdot\left(f^{2}\right)^{2}-a_{0}=0
$$

Cubic equation was solved using the source code developed by Professor Nam Sun Wang [3] (upon his approval) and contains the following steps:

$$
a^{*} x 3+b^{*} x 2+c^{*} x+d=0
$$


Step 1: Calculate p and q

$$
\begin{gathered}
\mathrm{p}=(3 * \mathrm{c} / \mathrm{a}-(\mathrm{b} / \mathrm{a}) 2) / 3 ; \\
\mathrm{q}=\left(2 *(\mathrm{~b} / \mathrm{a}) 3-9 * \mathrm{~b}^{*} \mathrm{c} / \mathrm{a} / \mathrm{a}+27 * \mathrm{~d} / \mathrm{a}\right) / 27
\end{gathered}
$$

Step 2: Calculate discriminant $\mathrm{D}$

$$
\mathrm{D}=(\mathrm{p} / 3) 3+(\mathrm{q} / 2) 2
$$

Step 3: Depending on the sign of $\mathrm{D}$, you follow different strategy.

If $\mathrm{D}<0$, three distinct real roots.

If $\mathrm{D}=0$, three real roots of which at least two are equal.

If $\mathrm{D}>0$, one real and two complex roots.

Step 3a: For $\mathrm{D}>0$ and $\mathrm{D}=0$

Calculate $\mathrm{u}$ and $\mathrm{v}$

$$
\begin{aligned}
& \mathrm{u}=\text { cubic_root(-q/2 }+ \text { sqrt(D)) } \\
& \mathrm{v}=\text { cubic_root(-q/2 }-\operatorname{sqrt}(\mathrm{D}))
\end{aligned}
$$

Find the three transformed roots

$$
\begin{aligned}
& \mathrm{y} 1=\mathrm{u}+\mathrm{v} \\
& \mathrm{y} 2=-(\mathrm{u}+\mathrm{v}) / 2+\mathrm{i}(\mathrm{u}-\mathrm{v}) * \operatorname{sqrt}(3) / 2 \\
& \mathrm{y} 3=-(\mathrm{u}+\mathrm{v}) / 2-\mathrm{i}(\mathrm{u}-\mathrm{v}) * \operatorname{sqrt}(3) / 2
\end{aligned}
$$

Step 3b: Alternately, for $\mathrm{D}<0$, a trigonometric formulation is more convenient

$$
\begin{aligned}
& \mathrm{y} 1=2 * \operatorname{sqrt}(\mid \mathrm{p} / / 3) * \cos (\mathrm{phi} / 3) \\
& \mathrm{y} 2=-2 * \operatorname{sqrt}(\mid \mathrm{p} / / 3) * \cos ((\mathrm{phi}+\mathrm{pi}) / 3) \\
& \mathrm{y} 3=-2 * \operatorname{sqrt}(|\mathrm{p}| / 3) * \cos ((\mathrm{phi}-\mathrm{pi}) / 3)
\end{aligned}
$$

Where: $\mathrm{phi}=\operatorname{acos}(-\mathrm{q} / 2 / \mathrm{sqrt}(|\mathrm{p}| 3 / 27))$

$$
\text { pi }=3.141592654 \ldots
$$

Step 4: Find the three roots

$$
\mathrm{x}=\mathrm{y}-\mathrm{b} / \mathrm{a} / 3
$$

\section{Worked Example to Analyze a Core Using the Structural Analysis Program Based on the Equivalent Column'S Method}

To demonstrate the analysis of a central core structure, a $75 \mathrm{~m}$ high building, consisting of 25 levels, $3.0 \mathrm{~m}$ - storyhigh, with the plan arrangement shown in Fig. 1 is considered. The resistance to forces in both directions and to torque is provided by a core whose dimensions and properties are determined. The building is subjected to uniformly distributed wind pressure of $14 \mathrm{kN} / \mathrm{m}$ in $\mathrm{x}$ direction and $-21 \mathrm{kN} / \mathrm{m}$ in $\mathrm{y}$ direction. The elastic modulus $\mathrm{E}=3.07 \times 10 \mathrm{kN} / \mathrm{m}$ and the shear modulus $\mathrm{G}=1.29 \times 107 \mathrm{kN} / \mathrm{m}$ are assumed for the concrete properties C20/25.

\subsection{Step1: Determine the Geometrical and Stiffness} Characteristics

For the given structure will determine the location of the shear center, the moment of inertia, warping constant and Saint-Venant torsional constant. The parameters of the central core are: $\mathrm{Ix}=11.53 \mathrm{~m}^{4}$; $\mathrm{Iy}=$ $52.37 \mathrm{~m}^{4} ; \mathrm{Iw}=17.93 \mathrm{~m}^{6} ; \mathrm{J}=19.28 \mathrm{~m}^{4}$. The bracing elements have no product of inertia Ixy $=0$. The radius of gyration is: ip $=10.4 \mathrm{~m}$.

The equivalent column is situated in the shear center of the core. The building core is mono symmetric and the location of the shear center in considered along the axis of symmetry.

\subsection{Step 2: Determine the Critical Load}

Under uniformly distributed load, the critical loads for sway buckling are determined using Timoshenko formula:

$$
\begin{aligned}
& \text { Ncr. } x=2058 * 10^{3} \mathrm{kN} \\
& \text { Ncr.y }=442.9 * 10^{3} \mathrm{kN}
\end{aligned}
$$

Determine torsional parameter: $\mathrm{k}=62.7344$ and parameter ks $=64.7107$.

If $k s=64.7107$, can obtained the critical load parameter $\alpha=4883.58$.

Knowing the critical load parameter $\alpha$, can be determined the critical load for pure torsion:

$\mathrm{Ncr}, \varphi=4065^{*} 103 \mathrm{kN}$

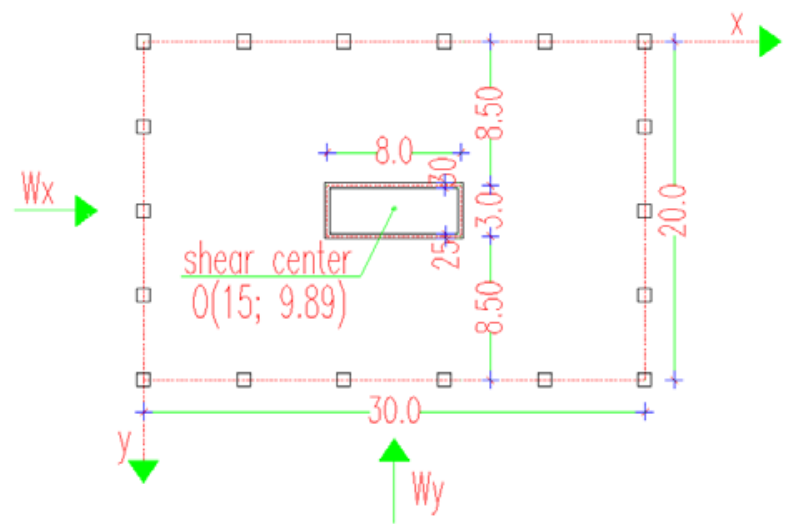

Fig. 1 Building's core structure. 
The cubic equation discussed at the third subparagraph takes into account the basic modes interaction. Solving the cubic equation for determining the critical load has been consistently that the direction of critical load is the y direction. The critical loads values, in both direct and for pure torsion, are presented in Table 1.

\subsection{Step3: Determine the Fundamental Frequency}

The first natural frequencies for the basic modes of vibration in principal directions:

$$
\begin{aligned}
& f x=0.3068 \mathrm{~Hz} \\
& f y=0.1423 \mathrm{~Hz}
\end{aligned}
$$

As a function of torsional parameter $\mathrm{k}$, it can be determined the value of frequency parameter $\eta$ (noted niu in the program). Knowing that $\mathrm{k}=62.7344$ results the value of frequency parameter $\eta=15.9436$. Having the frequency parameter it can be calculated the natural frequency for pure torsional vibration:

$$
\mathrm{f} \varphi=0.4918 \mathrm{~Hz} \text {. }
$$

Solving the cubic equation for determining the critical frequency has been consistently that the direction of critical frequency is in the y direction.

The fundamental frequency values in both direct and for pure torsion, are presented in Table 2.

\subsection{Step 4 Determine the Maximum Stresses and Deformations}

The torque around the shear center $\mathrm{mz}=1.54$ $\mathrm{kNm} / \mathrm{m}$.

The maximum translations at the top of the equivalent column on both directions $\mathrm{x}$ and $\mathrm{y}$ respectively, is calculated using the above Eqs. (12), (13): $\mathrm{u}_{\max }=0.0352 \mathrm{~m} ; \mathrm{v}_{\max }=-0.2457 \mathrm{~m}$. The

Table 1 Critical load.

\begin{tabular}{|c|c|c|}
\hline $\mathrm{N} \mathrm{cr,x}[\mathrm{kN}]$ & $\mathrm{N} c r, \mathrm{y}[\mathrm{kN}]$ & $\mathrm{N} \mathrm{cr}, \varphi[\mathrm{kN}]$ \\
\hline $2053 * 10^{3}$ & $442.9 * 10^{3}$ & $4065^{*} 10^{3}$ \\
\hline
\end{tabular}

Table 2 Fundamental frequency.

\begin{tabular}{|c|c|c|}
\hline fcr,x [Hz] & $\mathrm{f} \mathrm{cr,y}[\mathrm{Hz}]$ & $\mathrm{fcr}, \varphi[\mathrm{Hz}]$ \\
\hline 0.970 & 0.455 & 0.291 \\
\hline
\end{tabular}

displacement in $\mathrm{x}$ direction is smaller then $\mathrm{H} / 500$ but in ydirection $\mathrm{v}_{\max }=-0.2457 \mathrm{~m}$ is larger than $\mathrm{H} / 500=0.15$ $\mathrm{m}$. The performance of the building is not acceptable so it is required to increase the rigidity of the building structure.

The rotation of the equivalent column is equal to the rotation of the building. The maximum rotation of the structure is $\varphi_{\max }=0.006$.

To determine the maximum bending moments and maximum shear forces in the core is necessary to calculate the maximum bending moment factor $\eta_{M} \max$ and the maximum shear force factor $\eta_{\text {Tmax }}: \eta_{\text {Mmax }}=$ 0.063 and $\eta_{\mathrm{T} \max }=1.0159$.

To calculate the maximum bending moments and shear forces is take into account the wind load in both directions (qx and qy) which acts in the shear center of the building and also the external torque which develops rotation around the shear center.

Using the formulas given above is calculated the maximum shear forces in the core in both directions:

$\mathrm{T}_{\mathrm{X} \max }=1037 \mathrm{kN}$ and $\mathrm{T}_{\mathrm{Y} \max }=1050 \mathrm{kN}$ and the maximum bending moment in the core: $\mathrm{M}_{\mathrm{Xmax}}=$ $-39346 \mathrm{kNm}$ and $\mathrm{M}_{\mathrm{Ymax}}=59063 \mathrm{kNm}$.

The location of the maximum Saint-Venant torsional moment Mt,max depends by torsional parameter $\mathrm{k}$ and loading slope $\mu$. In this case $\mathrm{k}=$ 62.7344 and $\mu=0$, thus the location of Mt,max is at $\mathrm{z}$ $=0.066 \mathrm{H}$ and the maximum value is

Mt,max $=106 \mathrm{kNm}$ according to the formula above.

Assuming that the warping torsional moment is maximum at the base of the structure $\mathrm{z}=0$, the value of $\mathrm{Mw}, \mathrm{max}=115.5 \mathrm{kNm}$.

The output data of the program is presented in Table 3.

Table 3 Output data.

\begin{tabular}{|c|c|c|c|c|c|c|c|c|}
\hline $\mathrm{u}_{\max }[\mathrm{m}]$ & $\mathrm{v}_{\max }[\mathrm{m}]$ & $\varphi\left[{ }^{0}\right]$ & $\mathrm{T}_{\mathrm{xmax}}[\mathrm{kN}]$ & $\begin{array}{c}\mathrm{T}_{\mathrm{ymax}} \\
{[\mathrm{kN}]}\end{array}$ & $\begin{array}{c}\mathrm{M}_{\mathrm{xmax}} \\
{[\mathrm{kNm}]}\end{array}$ & $\begin{array}{c}\mathrm{M}_{\mathrm{ymax}} \\
{[\mathrm{kNm}]}\end{array}$ & $\begin{array}{c}\mathrm{M}_{\text {tmax }} \\
{[\mathrm{kNm}]}\end{array}$ & $\begin{array}{c}\mathrm{M}_{\mathrm{wmax}} \\
{[\mathrm{kNm}]}\end{array}$ \\
\hline 0.0352 & -0.2457 & $0.006^{0}$ & 1050 & 1575 & -39346 & 59063 & 106 & 115.5 \\
\hline
\end{tabular}




\section{Conclusion}

Making an approximate analysis it can be verify the results obtained by FEM. If the two calculation methods, approximate and exact method, indicate the same spatial behavior of the structure, means that results are correct. Thus, to demonstrate the accuracy of the calculation method, presented and applied in this paper, the core center structure was calculated also by a computer program based on the FEM. The results obtained by FEM are similar with the results obtained in the computer program developed in MatLab. Having this computer program can be done a quick check for verifying the critical load, fundamental frequency, stresses and deformations of the structure.

\section{References}

[1] Karoly A. Zalka, Global Structural Analysis of Buildings, Taylor \& Francis e-Library, 2002

[2] B. Stafford Smith and A. Coull, Tall Buildings Structures: Analysis and Design, Wiley-Interscience Publication, 1991.

[3] Nam Sun Wang, Source code for cubic equation solver, available online at: http://terpconnect.umd.edu/ nsw /ench250/cubiceq.htm.

[4] R. Agent and T. Postelnicu, Calculul structurilor $\mathrm{cu}$ diafragme din beton armat, Editura Tehnica. 